\title{
IMPROVED PERFORMANCE OF LNA USING HIGH QUALITY FACTOR PGS ON-CHIP SPIRAL INDUCTORS
}

\author{
Mahmoud A. Abdelghany, Yehia S. Mohamed, AsmaaR.Wardany \\ Electrical Engineering Department, El-Minia University, El-Minia, Egypt \\ eng_abdelghany1979@yahoo.com
}

\begin{abstract}
This paper presents a detailed study of on-chip spiral inductors with patterned ground shield (PGS) inserted between the spiral inductorand the silicon substrate. This new design has been implemented in source degeneration cascode lownoise amplifier (LNA) circuit to show how the PGS inductors improve the performance of the circuit. An operation in 1.8V supply voltage, source degeneration cascode LNA structure was studied with both technology and PGS inductors. In this paper, the Agilent ADS (Advanced Design System) simulation software and TSMC $0.18 \mu \mathrm{m}$ CMOS process parameters were adopted to achieve the low-cost characteristics and high integration to fit the performance of $2.4 \mathrm{GHz}$ LNA design under IEEE 802.11a specification.According to the co-simulation results, the forward gain (S21) improved from 13.432 to $21.474 \mathrm{~dB}$, and the (S12)is below the typical value of $-15 \mathrm{~dB}$. The input impedance (S11) and the output impedance (S22) also represented good performance. In addition, the minimum noise figure was quite good. Thus, the LNA circuit with PGS inductorswas better in the availability and the possibility of $802.11 \mathrm{a}$ specification.
\end{abstract}

Keywords: on-chip inductors,patterend ground shield,cascade amplifier,IEEE 802.11a.

\section{Introduction}

Inductors are one of the key factors that determine the performance of RF-IC's. Among them, spiral inductors receive great attention due to their relatively high performance. It is frequently used in voltage-controlled oscillators (VCO's), low noise amplifiers (LNA's), mixers, and intermediate frequency filters (IFF's). There are two types of on-chip inductor: bond wirewounded and planar spiral inductor. The planar spiral inductor has advantages of minimizing the chip size, reducing wiring requirement, and delay time.Currently, there are many types of planner spiral inductors according to its geometry: square, hexagonal, octagonal and circle.

The need for integrated circuits with high Qfactor's inductors has been increasing recently. The spiral inductors on Si-based RFICs have suffered from low Q-factor due to their capacitive and electromagnetic coupling with the substrate at high frequencies. Therefore, it is one of the most intensively researched topic in RFICs. The Qfactor of the inductor is limited by the resistive losses in the spiral coil and by the substrate losses. Previous works have been done for improving the Q-factor of on-chip inductors, layout optimization, non-uniform metal width and nonuniform coil spacing, parallel current path, differential excitation, negative resistance, and a pattern ground shield (PGS) [1-6]. Because of the advantages of the PGS, we will use it to enhance the Q-factor of the three inductors.

The LNA is a key component that is typically placed at the front end of a radio receiver circuit. By using a low noise amplifier, the effect of noise from subsequent stages of the receiving chain is diminished by the gain of the amplifier. The radio frequency receivers consider (LNA) as their backbone. In this work, it has been used as atest circuit. 


\section{Modeling of spiral inductor}

A lumped circuit model of on-chip spiral inductor grown on Si substrate is shown in Figure (1) [7]. $\boldsymbol{L}_{\boldsymbol{s}}$ and $\boldsymbol{r}_{\boldsymbol{s}}$ are the series inductance and resistance of the spiral respectively. $\boldsymbol{C}_{\boldsymbol{s}}$ is the overlap capacitance between the turns of spiral and the cross-under layer. $\boldsymbol{C}_{\boldsymbol{o x}}$ is the oxide capacitance between the spiral and the substrate. $\boldsymbol{R}_{\boldsymbol{s i}}$ and $\boldsymbol{C}_{\boldsymbol{s i}}$ are the parameters modeling substrate losses and capacitive effects, respectively.

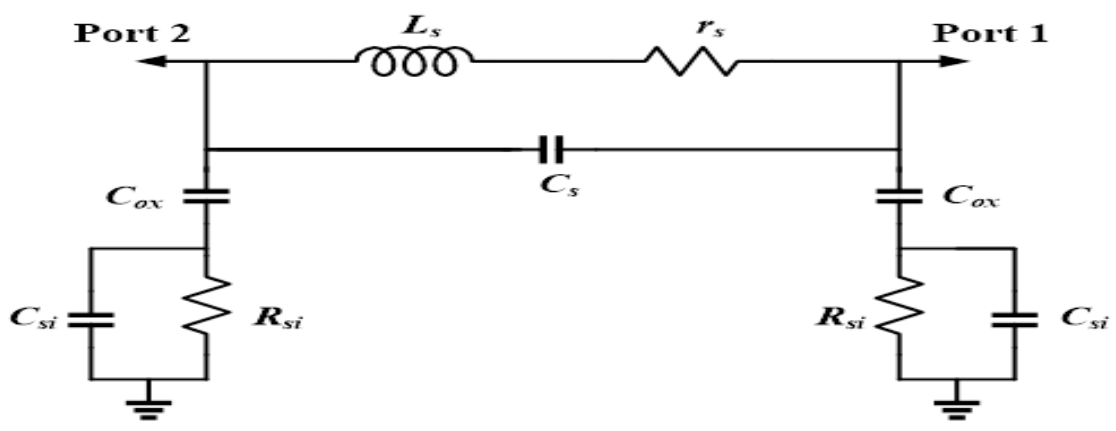

Fig. 1: Lumped model of a spiral inductor

The inductance of a spiral is a complex function of its geometry and includes both self and mutual inductances. The expressions for on-chip spiral inductor parameters are given by [7]:

$$
\begin{aligned}
& L_{S}=\frac{\mu l}{2 \pi}\left\{\left[\ln \left(\sqrt{1+\left(\frac{1}{4 N d^{+}}\right)^{2}}+\frac{l}{4 N d^{+}}\right)-\sqrt{1+\left(4 N d^{+}\right)^{2}}+\frac{4 N d^{+}}{l}\right]\right\} \\
& r_{S}(\omega)=\frac{l}{\omega \cdot \sigma \cdot \delta(\omega) \cdot\left(1-e^{\frac{t}{\delta}}\right)} \quad(3) \quad \mathrm{C}_{\mathrm{S}}=\mathrm{n} \cdot \mathrm{w}^{2} \cdot \frac{\varepsilon_{\mathrm{OX}}}{\mathrm{t}_{\mathrm{OXX} 1-\mathrm{M} 2}}
\end{aligned}
$$

$C_{O X}=l . w \frac{\varepsilon_{\mathrm{OX}}}{\mathrm{t}_{\mathrm{OX}}}$

$C_{s}=N \cdot C_{o v}=N \cdot w^{2} \cdot \frac{\varepsilon_{O X}}{d}$

$$
\begin{array}{r}
R_{S i}=\frac{2}{l \cdot w \cdot G_{s u b}} \\
C_{S i}=\frac{l \cdot w \cdot C_{S u b}}{2}
\end{array}
$$

wherel is the wire length, $w$ is the width of the metal conductor, and $t$ is the thickness of the metal conductor.

There are basically three types of capacitances in an on-chip inductor[8]:

(1) the series capacitance $C_{S}$ between metal lines, is given by: wheren is the number of overlaps, $w$ is the spiral line width, and $t_{O x M 1-M 2}$ is the oxide thickness between the spiral.

(2) the oxide capacitance $C_{o x}$ associated with the oxide layer, is given by:

$$
C_{o x}=\frac{1}{2} \cdot l_{t} \cdot w \cdot \frac{\varepsilon_{o x}}{t_{o x}}
$$

where $t_{o x}$ is the oxide thickness underneath the metal. 
(3) the coupling capacitance $C_{s i}$ associated with the Si substrate, is given by:

$$
C_{s i}=\frac{1}{2} \cdot l_{t} \cdot w \cdot C_{s u b}
$$

where $C_{s u b}$ is the capacitance of the substrate.

\section{LNA Circuit Structure}

Figure 2(a) shows the complete schematic circuit of $2.4 \mathrm{GHz}$ cascode LNA. The method employed here is inductive source degeneration. The degeneration inductor (L2) enables more flexibility in matching the input stage to $50 \Omega$. It is also used to improve the stability and linearity of the LNA. Inductive load (L3) at the drain of cascading transistor compensates for the degradation in gain at high frequency. Thisinductor is used to set the resonant frequency. The greater the value of L3, the greater will be the gain. Nevertheless, it is not practical to make L3 very high, because high inductive values will result in low self-resonant frequency. Accordingly, the nominal value of $4.1 \mathrm{nH}$ is chosen for L3 [9]. Cascoding transistor is used to reduce the interaction of the gate-drain capacitance of lower transistor and also improves the reverse isolation S12. This topology is one of the most popular LNA topologies due to its merit of low power consumption, high gain, and high reverse isolation. In the design of low noise amplifiers, there are several common goals. These include noise figure (NF), Gain, linearity, input and output matching, power consumption, and stability. Figure 2(b) shows the same circuit, but with PGS inductors instead of the technology inductors, which will be discussed later.

In this section, three inductors have been designed using Momentum optimization tool of ADS2009, which exist in the previous LNA circuit (see Fig.1(a)). Momentum is a threedimensional planar electromagnetic (EM) simulator that enables RF and microwave designers to significantly expand the range and accuracy of the passive circuits and circuit models [10].Figure 3(a) shows the layout ofthe inductive load (L3), which has 5.5 turns, a radius of $30 \mu \mathrm{m}$, and width of $6 \mu \mathrm{m}$ on metal layer 6 . Figure 3(b) shows the layout of the matching inductor (L4), which has 5.5 turns, a radius of $40 \mu \mathrm{m}$, and width of $6 \mu \mathrm{m}$ on layer 6 . Figure 3(c) shows the layout of The source degeneration inductor (L2), which has half turn, a radius of $40 \mu \mathrm{m}$, and width of 6 $\mu \mathrm{m}$ on layer 6 .

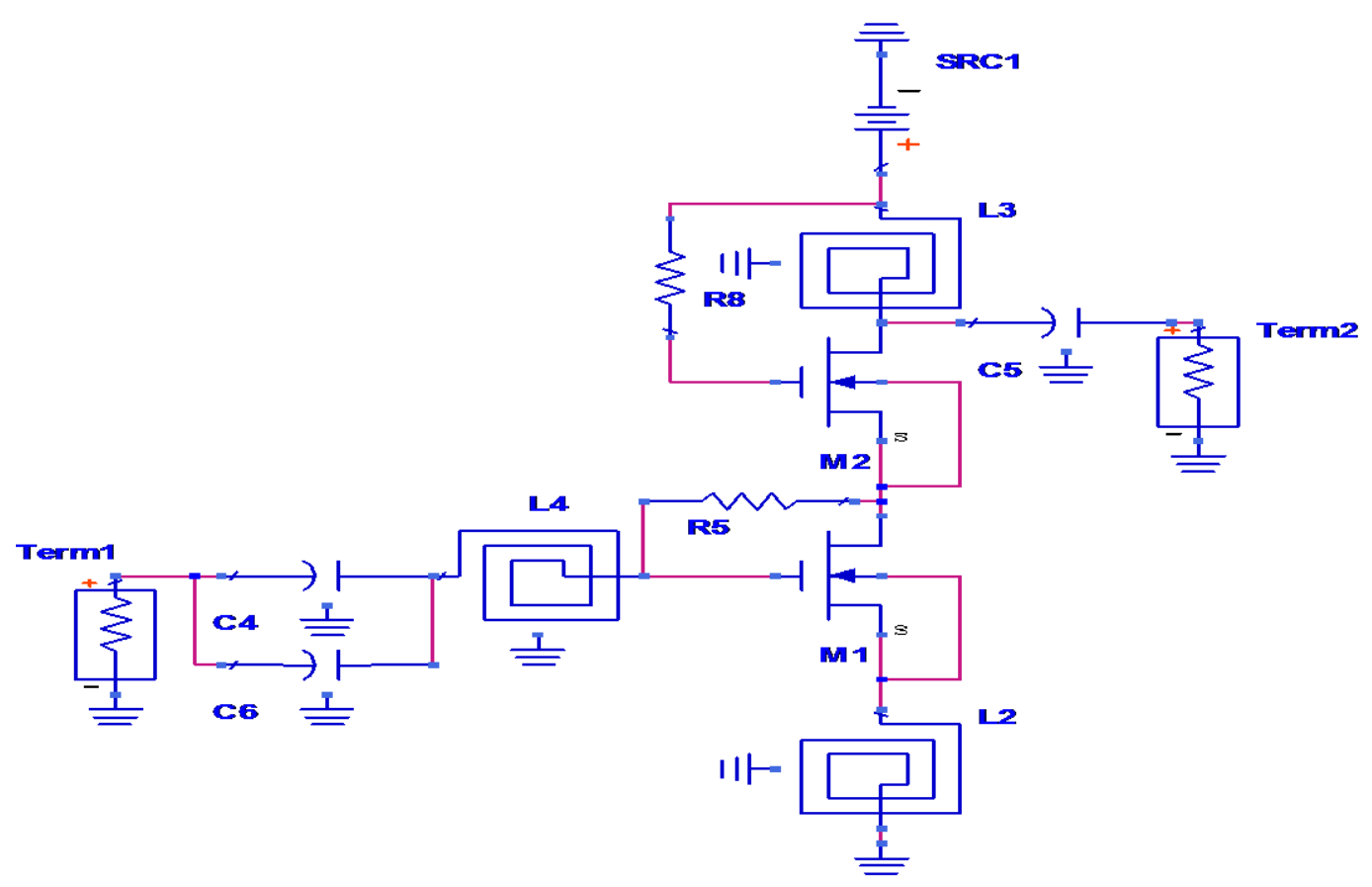

(a) 


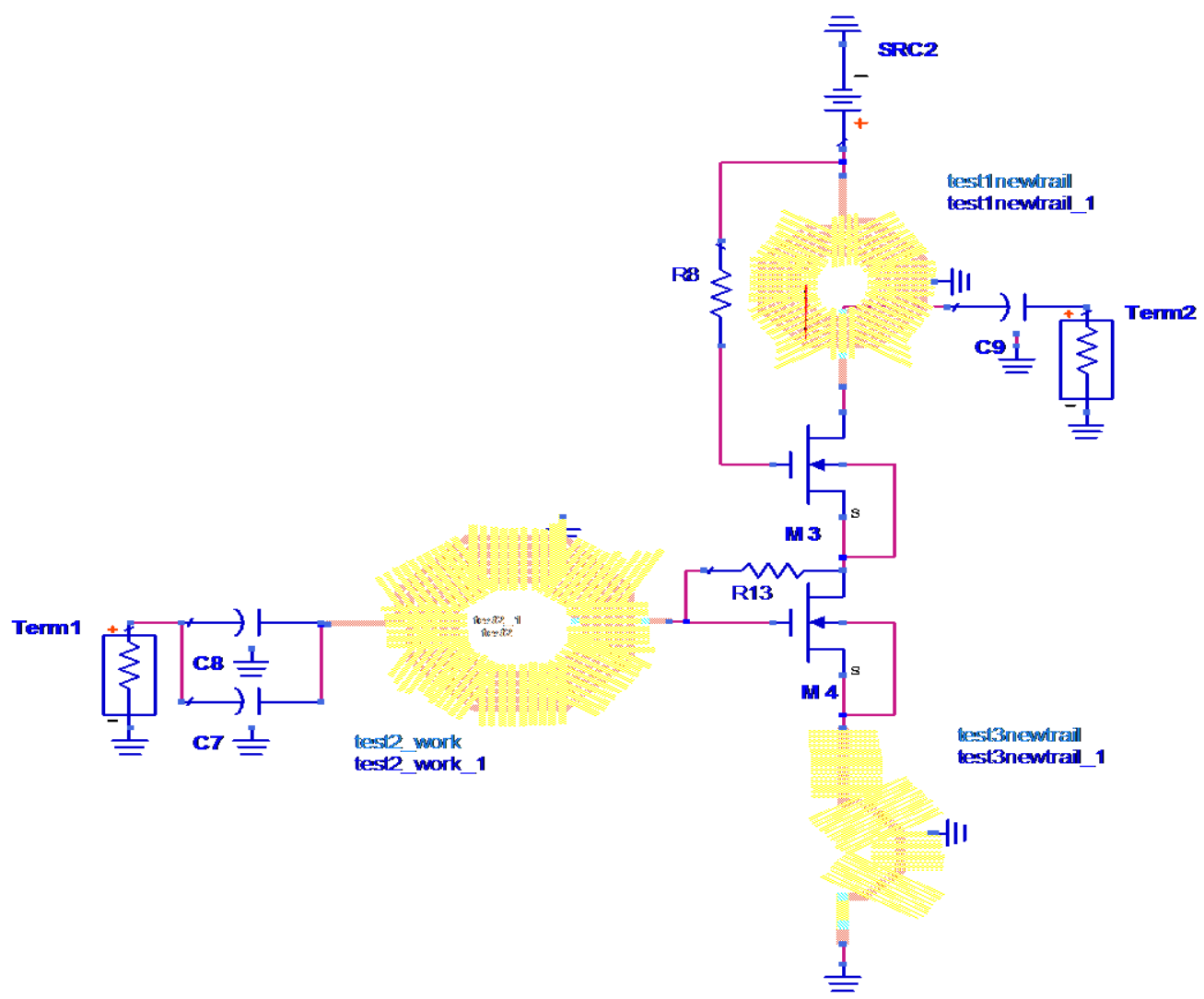

(b)

Fig.2 : (a) LNA circuit, (b) the LNA circuit with PGS inductors.

There are other advantages of PGS such as; 1the behavior of the inductor, which is easier to model, especially at differenttemperatures,2Inductor behavior is independent of variations in substrateresistivity and type (e.g. bulk, epi and SOI). [8].Figure 3(d) shows the inductive inductor with PGS simulated with the momentum tool of

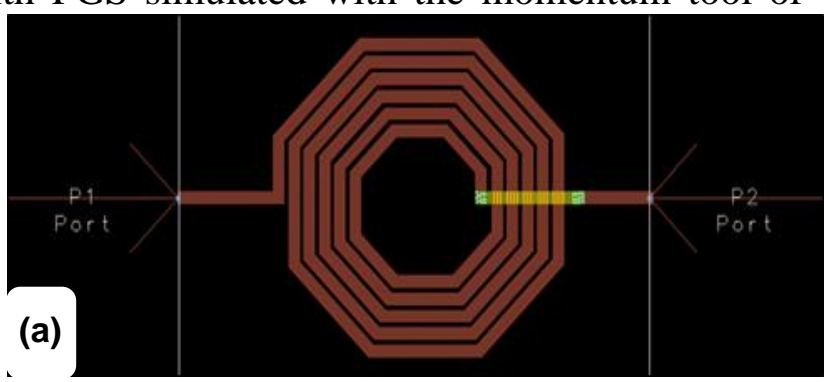

ADS 2009. Note that the slots in the PGS are orthogonal to the direction of current flow in the spiral inductor to increase the resistance to the image current [11]. Similar behavior is shown in Fig.3(e) and 3(f)for the matching inductor with PGS and the source degeneration inductor with PGS, respectively.

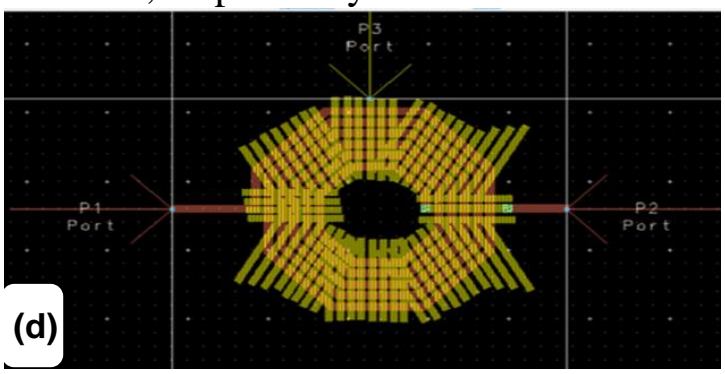



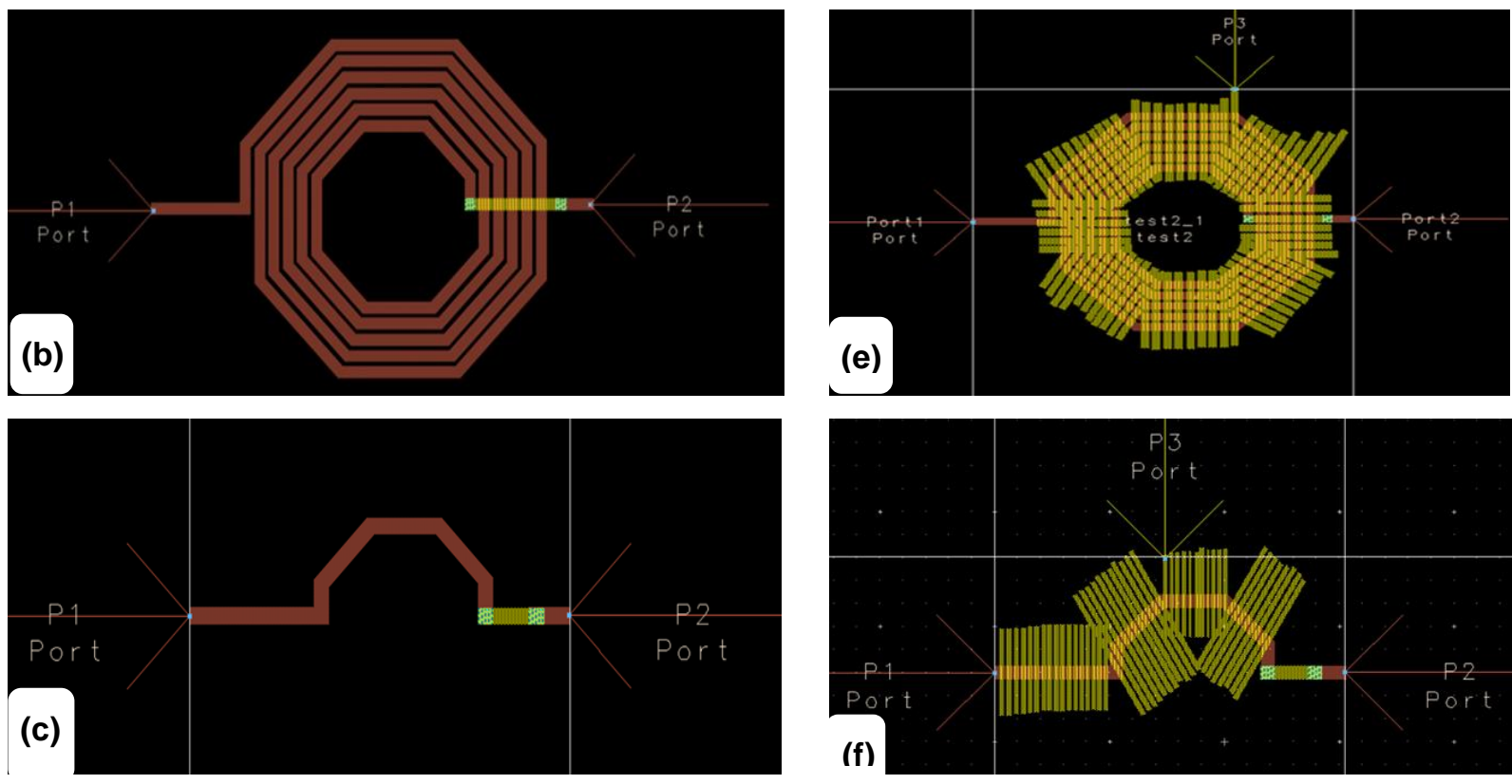

Fig.3 : (a) layout of the The inductive load (L3), (b) layout of the The matching inductor (L4), (c):layout of The source degeneration inductor (L2), (d): layout of the the inductive inductor with PGS, (e): layout of the matching inductor with PGS, (f): layout of The source degeneration inductor with PGS.

\section{Results and Discussion}

\subsection{Spiral inductor with and without shield:}

The simulation results of the Q-factor with frequency for the conventionalL2, L3 and L4 and PGS inductorsare shown in Figures (4), (5), and (6) respectively. It can be noticed that at $2.4 \mathrm{GHz}$, the Q-factor of the PGSinductor wasenhanced by approximately $65 \%$.For the matching inductor, theQ-factor enhanced by $60 \%$. Regarding the source degeneration inductor, it has a different shape because it has a half turn, even though, the enhancement percentage was $40.6 \%$.

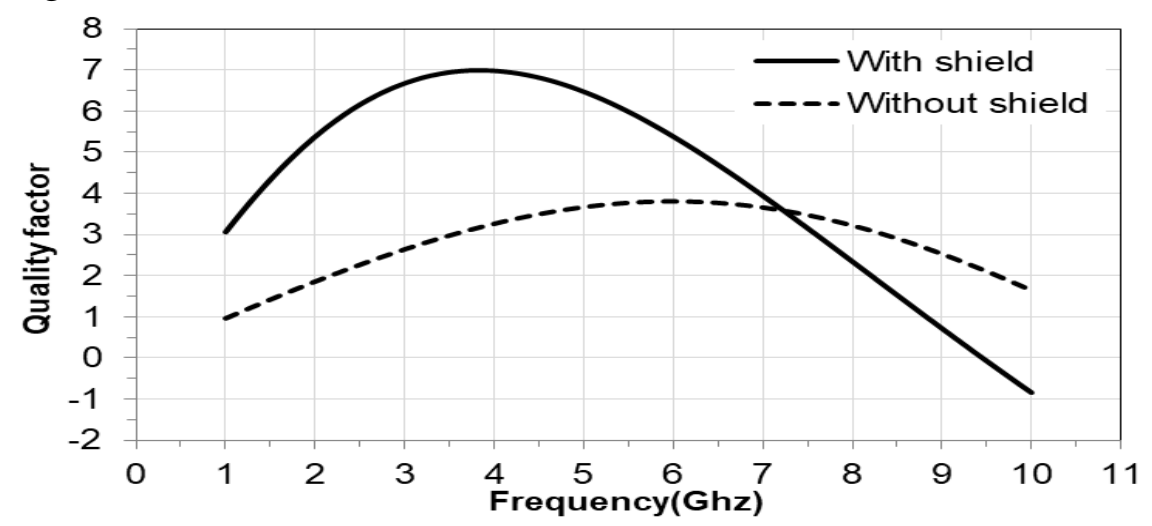

Fig.4 : Comparison of the Q-factor versus frequency of inductive inductor with and without PGS. 


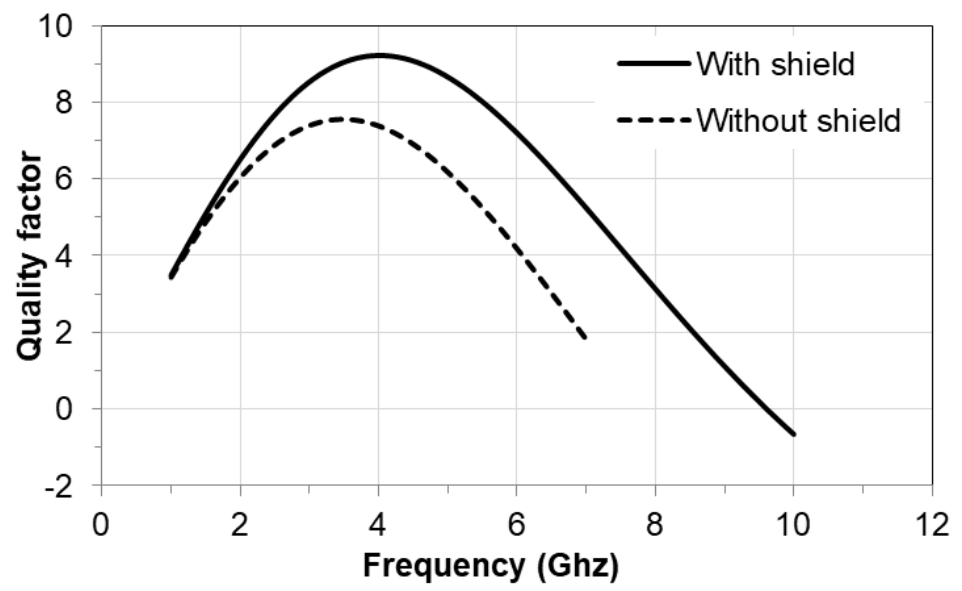

Fig.5 : Comparison of the Q-factor versus frequency of matching inductor with and without PGS.

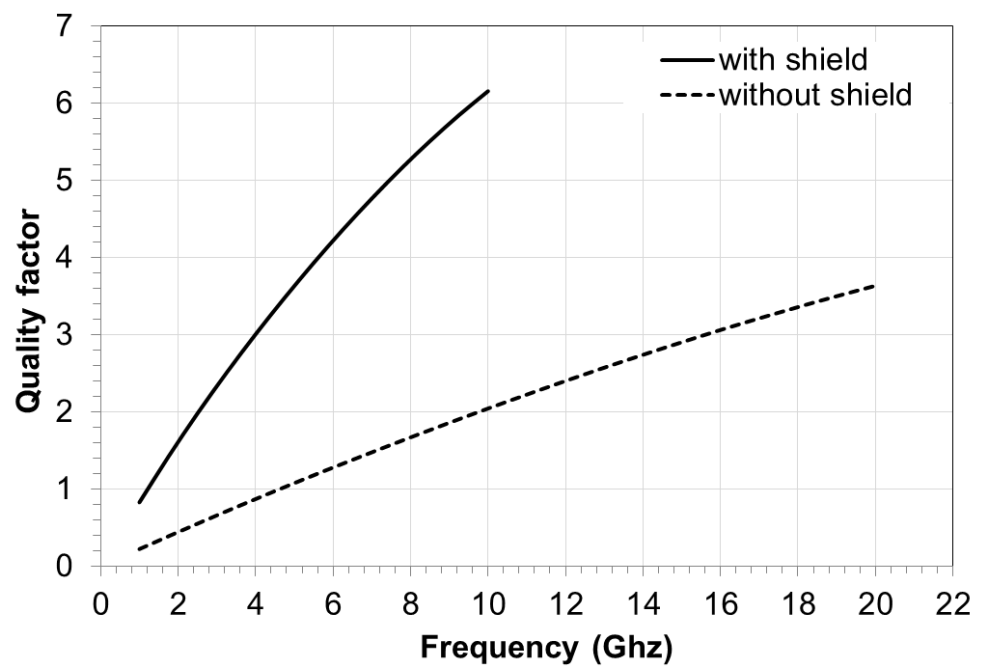

Fig.6 : Comparison of the Q-factor versus frequency of The source degeneration inductor with and without PGS.

4.2 Co-simulation results:

S-Parameter simulation is used to describe thesignal characteristics including the amplitude, phase andfrequency distribution is a more pertinent expression. Thescattering parameters usually have four part two-portnetwork system: input return loss(S11), output return loss(S22),reverse isolation(S12) and forward voltage gain(S21), as shown in Figure (7). There are the import voltage signal (a1), thereflected signal (b1), and the transmitted signal into the network through amplification or attenuation after the output signal (b2) to the load. If the impedance of output port will not fully match the load, some output signal will be reflected into the network system as voltage signal (a2) generation[12].

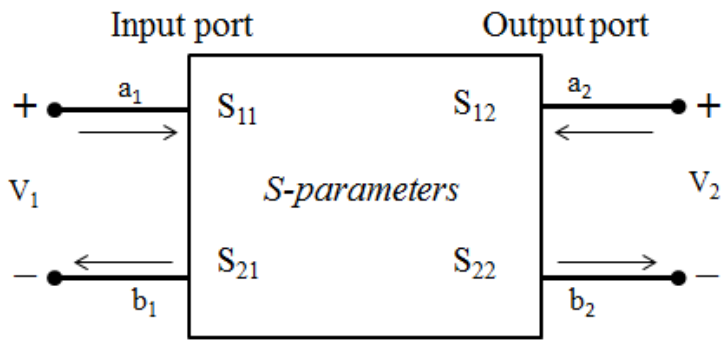

Fig.7 : Schematic block of a two-port network system.

The LNA circuit with PGS conductors has been simulated with inductive load, matching, and source degeneration, which has been designed using TSMC $0.18 \mu \mathrm{m}$ technology, and simulated by Advanced Design System (ADS2009) at 2.4GHz.

Adopting the ADS simulation software and device and process models in simulation with 
TSMC $0.18 \mu \mathrm{m}$ CMOS process, the cascode LNA exhibited good performance. The circuit performance is more impressive. Here, the operating voltage of this $2.4 \mathrm{GHz}$ LNA was a $1.8 \mathrm{~V}$ supply voltage. The final simulation results show that the gain of the LNA circuit with PGS conductors enhanced from $13.14 \mathrm{~dB}$ to $21.474 \mathrm{~dB}$ as shown in Figure (6). In the PGS LNA circuit, the reverse isolation (S11) is smaller than that appear in the LNA circuit using technology inductors as shown in Figure(8).

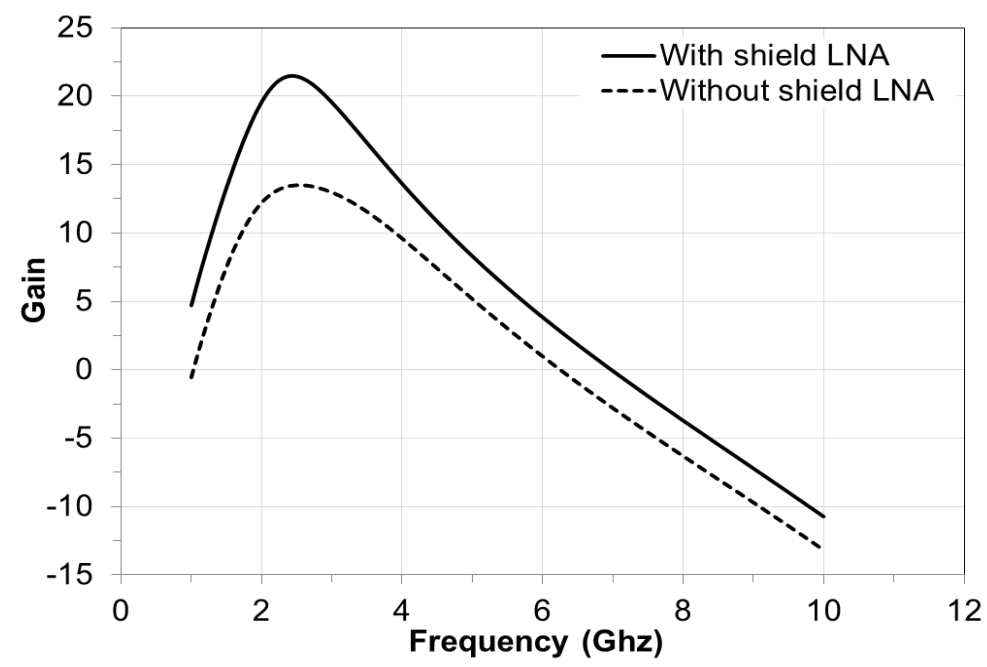

Fig.8 : Comparison of the Gain (S21) versus frequency of LNA circuit with and without PGS.

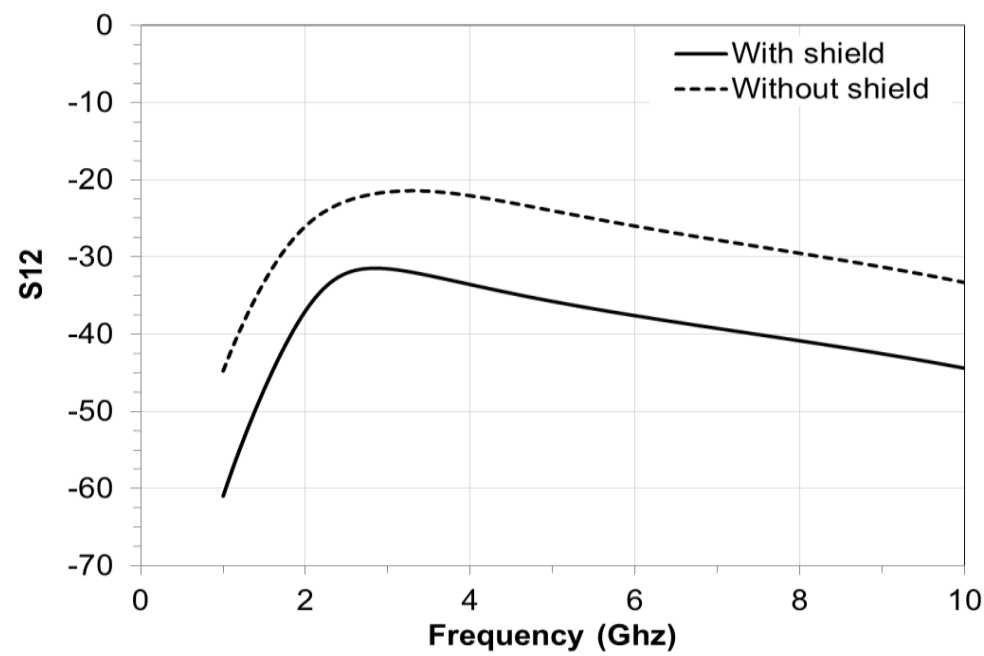

Fig.9 : Comparison of the reverse isolation (S12) versus frequency of LNA circuit with and without PGS.

The input return loss $\left(\mathrm{S}_{11}\right)$ improvedfrom -4.489 to $-7.556 \mathrm{~dB}$ and the output return loss $\left(\mathrm{S}_{22}\right)$ also improved from -16.866 to $-11.794 \mathrm{~dB}$, as shown Figure (9) and (10) respectively. They have good performance. Finally, minimum noise figure performance is quite good, as shown in Figure(11). 
Journal of Advanced Engineering Trends (JAET), Vol. 38, No. 2. July 2019

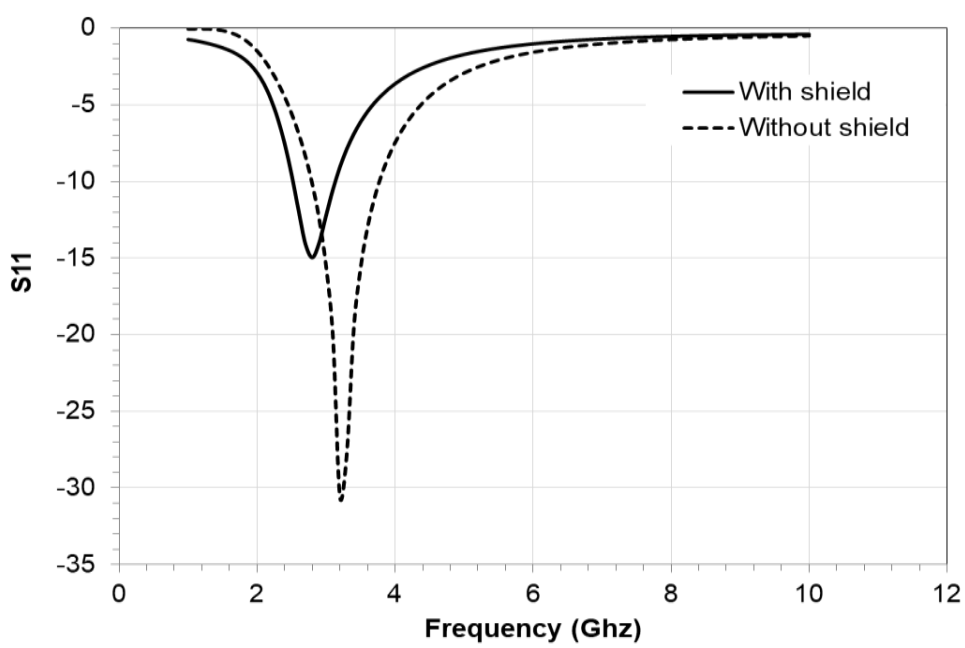

Fig.10 :Comparison of the input returns loss (S11) versus frequency of LNA circuit with and without PGS.

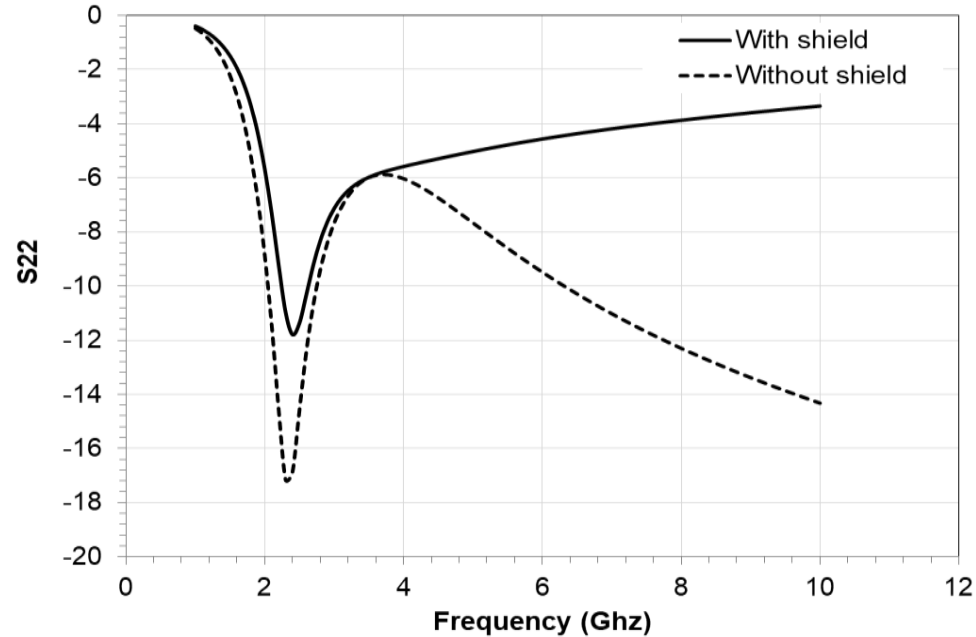

Fig.11 :Comparison of the output return loss (S22) versus frequency of LNA circuit with and without PGS.

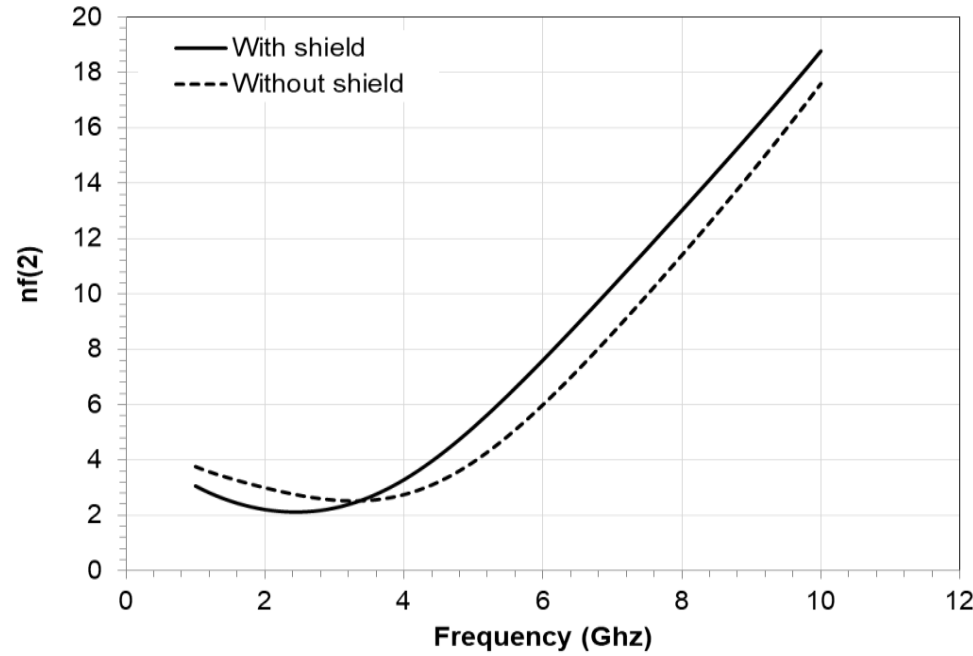

Fig.12 :Comparison of the minimum noise figure nf(2) versus frequency of LNA circuit with and without PGS. 
5. Comparison Between the proposed LNA With Other LNAs.

Table 1 shows a comparison between the simulation results of LNA with and without PGS. It be noticeable thatthe inductors with PGS improve the performance of the circuit
.Table 2 shows the comparison of the proposed LNA with PGS inductors with the other works of LNA . It shows how the proposed LNA with PGS inductors exhibits a high impedance matching, high gain and low noise figure as compared to the other reported LNA.

Table 1: Summary of simulation results

\begin{tabular}{|c|c|c|}
\hline Parameters & LNA with technology inductors & $\begin{array}{c}\text { LNA with PGS } \\
\text { inductors }\end{array}$ \\
\hline S11 & $-4.489 \mathrm{~dB}$ & $-7.556 \mathrm{~dB}$ \\
\hline S12 & $-23.162 \mathrm{~dB}$ & $-32.559 \mathrm{~dB}$ \\
\hline Gain (S21) & $13.432 \mathrm{~dB}$ & $21.474 \mathrm{~dB}$ \\
\hline S22 & $-16.866 \mathrm{~dB}$ & $-11.794 \mathrm{~dB}$ \\
\hline Noise figure NF(2) & $3.501 \mathrm{~dB}$ & $2.118 \mathrm{~dB}$ \\
\hline
\end{tabular}

Table 2: Comparison between the proposed LNA with PGS inductors and other works

\begin{tabular}{|c|c|c|c|c|c|}
\hline Parameters & {$[9]$} & {$[13]$} & {$[14]$} & {$[15]$} & $\begin{array}{c}\text { Proposed } \\
\text { LNA with PGS } \\
\text { inductors }\end{array}$ \\
\hline RF freq.( GHz) & 2.4 & 2.4 & $3.7-4.2$ & 5.8 & 2.4 \\
\hline S11(dB) & -17.052 & -12.21 & -23.8 & -18.9 & -7.556 \\
\hline S12 (dB) & -13.029 & -39.31 & -43.5 & -22.1 & -32.559 \\
\hline Gain S21(dB) & 11.352 & 16.64 & 25.4 & 19.5 & 21.474 \\
\hline S22(dB) & -21.956 & -12.995 & -17.5 & -20.0 & -11.794 \\
\hline Noise figure NF(2) & 0.216 & 4.262 & 1.06 & 1.2 & 2.118 \\
\hline
\end{tabular}

\section{Conclusion and Contribution}

In this work, a detailed study of a spiral inductor on silicon with a patterned ground shield has been presented. The effects of pattern have been demonstrated. simulated results show that the new design improves Q-factor and inductance.Upon using LNA circuit, we show that the inductors with PGS improve the performance of the circuit.

\section{References}

[1] José M. López-Villegas, Member, IEEE, JosepSamitier, Member, IEEE, Charles
Cané, Pere Losantos, and Joan Bausells, Member, IEEE, "Improvement of the Quality Factor of RF Integrated Inductors by Layout Optimization", IEEE transactions on microwave theory and techniques, Vol. 48, No. 1, 76-83, 2000.

[2] Shen Pei, Zhang Wanrong, Huang Lu, Jin Dongyue, and XieHongyun, "Improving the quality factor of an RF spiral inductor with non-uniform metal width and non-uniform 
coil spacing", Journal of Semiconductors, Vol. 32, No. 6, 064011-1-5, 2011.

[3] DongwooSuh, BongkiMheen, "Analysis on the effect of parallel current path on the quality factor of CMOS spiral inductors for 1-10 GHz", Microelectronic Engineering, Vol. 77(3-4), 292-296, 2005.

[4] M.T. Reiha, T. Y. Choi, J.-H. Jeon, S. Mohammadi, L.P.B. Katehi, "High-Q differential inductors for RFIC design", Microw. Conf. 2003. 33rd Eur., 2003, 127130.

[5] S. Wang, R.X. Wang, "A tunable bandpass filter using Q-enhanced and semipassive inductor at S-Band in 0.18um CMOS”, Prog. Electromagn.Res. B, Vol. 28, 55-73, 2011.

[6] C. Patrick Yue and S. Simon Wong, "OnChip Spiral Inductors with Patterned Ground Shields for Si-Based RF IC's", IEEE journal of solid-state circuits, Vol. 33, No. 5, 743752, 1998.

[7] El-Sayed A. M. Hasaneen, NagwaOkely, "On-Chip Inductor Technique for Improving LNA Performance Operating at $15 \mathrm{GHz}$ ", Circuits and Systems, 3, (2012) 334-341.

[8] C. Patrick Yue and S. Simon Wong,"Physical modeling of spiral inductors on silicon", IEEE Transactions on Electron Devices, 47(2000) 560-568.

[9] HafizaAbid, NoureenOwais, Design of High Linearity,"Low Noise GaAs Based Single Ended Low Noise Amplifier", journal of space technology, Vol. 4, No. 1, 55-60, 2014.

[10] KanchanaSurendra,"Modeling and Design of a Three- dimensional Inductor with Magnetic Core",M Sc. Thesis, The faculty of the Virginia Polytechnic Institute and State University, 2011 Blacksburg, VA.

[11]Kalluru Chan Basha, "Electromagnetic analysis of spiral inductor with patterned ground shields",International Journal of
Latest Research in Science and Technology,Vol. 6, Issue 4: 56-57, 2017.

[12]Hsin-Chia Yang1, Ssu-Hao Peng1, SheaJue Wang2,b, Mu-Chun Wang1,a, Chun-Wei Lian1, Jie-Min Yang1, Hung-I Chin1, Chuan-Hsi Liu3,"High Quality of $0.18 \mu \mathrm{m}$ CMOS 5.2GHz Cascode LNA for RFID Tag Applications,IEEE 2nd International Symposium on Next-Generation Electronics (ISNE) - February 25-26 , Kaohsiung , Taiwan.

[13]JonGuerber,"Design of an 2.4 GHz CMOS Low Noise Amplifier”, Winter 2010.

[14] Tran Van Hoi, Nguyen Xuan Truong and Bach Gia Duong,"Design and Fabrication of High Gain Low Noise Amplifier at 4 GHz",International Journal of Engineering and Innovative Technology (IJEI Volume 4, Issue 7, January 2015.

[15] Abu Bakar Ibrahim, Abdul Rani Othman, Mohd Nor Husain, and Mohammad SyahrirJohal,"The Cascode and Cascaded Techniques LNA at $5.8 \mathrm{GHz}$ Using TMatching Network for WiMAX Applications",International Journal of Computer Theory and Engineering, Vol. 4, No. 1, February 2012. 


\section{الملخص العريي}

تقدم هذه الورقة دراسة تفصيلية للمحثات الحلزونية على الرقاقة ذات الدرع الأرضي المنقوش (PGS)الذي يتمإدخاله بين المحفز اللولبي وطبقة السيليكون. تم تتفيذ هذا التصميم الجديد في دائرة مضخم الضوضاء المنخفض (LNA) من نوعcascodeلإظهار كيف أن محاثات PGS تحسن من أداء الدائرة. تمت دراسة عملية في جهد الإمداد 1.8 فولت ، بنية LNA لكود الثفرة المصدر مع كل من المحاثات التقنية و . Agilent ADS في هذه الورقة ، تم اعتماد برنامج محاكاة التصميم المتقدم) ومعلمات عملية مS لتحقيق خصائص منخفضة التكلفة والتكامل العالي لتتتاسب مع أداء تصميم LNA 2.4 LNA 2.18 ميجاهرتز وفقًا لمواصفات .IEEE 802.11a ووفقًا لنتائج المحاكاة المشتركة ، تحسنت الكسب إلى الأمام (S21) من 13.432 إلى 21.474 إلى ديسييل ، وكان (S12) أقل من القيمة النموذجية عند -dB. 15) ممانعة الإدخال (S11) ومقاومة الخرج (S22) أيضًا أداءً جيدًا. بالإضافة إلى ذلك ، كان أقل رقم ضجيج جيد. وبالتالي ، كانت دارة LNA مع محاثات PGS أفضل في توافر وإمكانية مواصفات . a.802.11 